\title{
MODIFICATION FOR THE ENGSTRÖM ER300 RESPIRATOR TO PREVENT CORROSION
}

\author{
K.W. Turnbull, B.A.SC., M.D., ${ }^{*}$ F.W. MCCaffrey, M.D., $\uparrow$ \\ AND W.A. MASON
}

Sterilization AND AERATion with adequate drying of respiratory parts has sometimes been a problem with ventilating equipment. Pooling of secretions prior to sterilization usually requires thorough washing and cleansing of the respirator. Vigorous attention to prevention of pooling after the sterilization may also be necessary to avoid respirator corrosion. When the Engström ER300 Respirator§ was used for prolonged ventilatory support at St. Paul's Hospital in Vancouver some pooling and fluid collection occurred in the self-contained patient system. This could not be prevented either before or after autoclaving by the aeration or drainage regimes in use. We have solved this problem by using a baked phenolic lining ("Hersite") I which is similar to teflon. This lining prevents corrosion of the cast

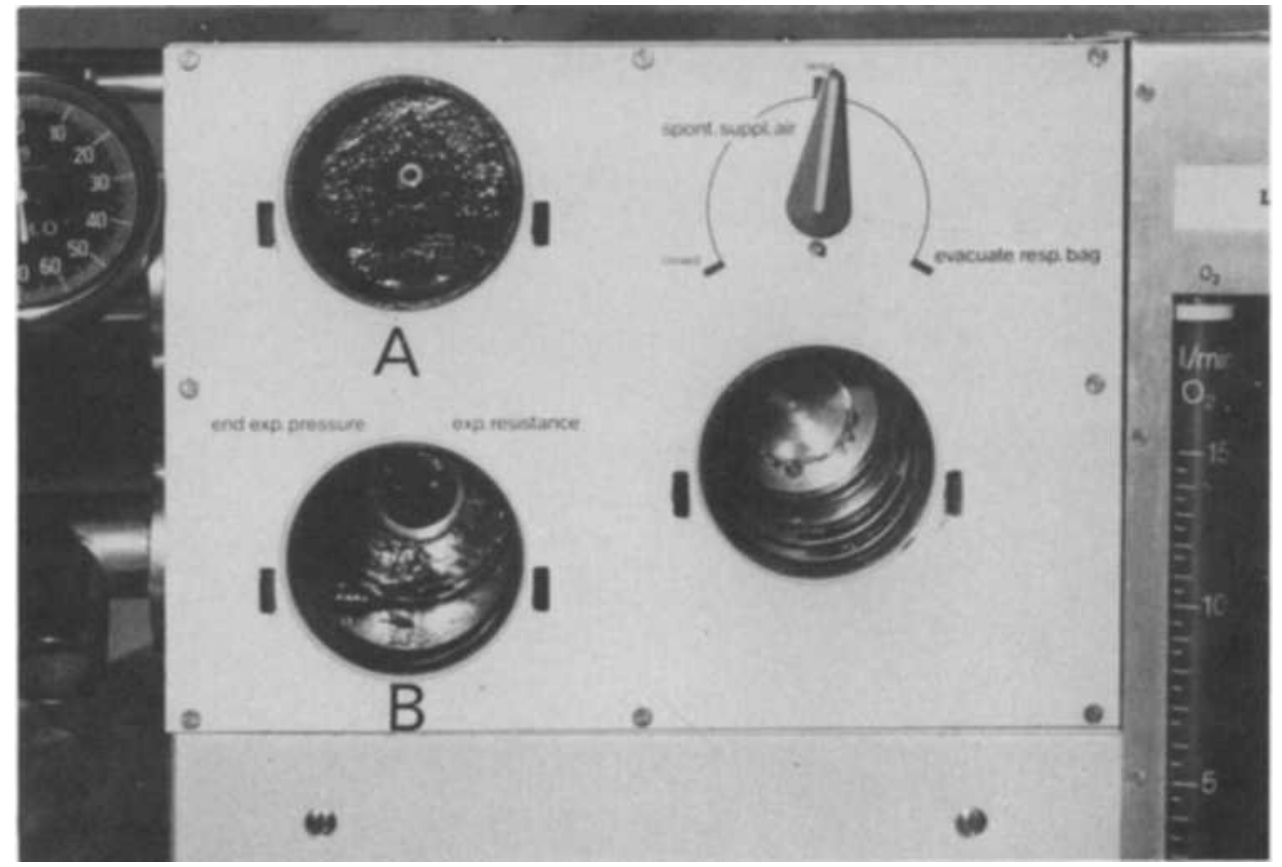

Figure 1. Patient System of Engstrom ER300 Ventilator with Expiratory Valve (A) and Expiratory Resistance Control (B) removed to show "Hersite" lining in place.

-Department of Anaesthesia, Vancouver General Hospital, Vancouver, B.C.

†Department of Anaesthesia, St. Paul's Hospital, Vancouver, B.C.

$\$$ Department of Technical Development, St. Paul’s Hospital, Vancouver, B.C.

\$L. K. B. Medical AB, Box 11075.S.1611, Bromma, Sweden.

đ"Hersite" is a patented product of Hersite \& Chemical Co., Manitowac, Wisconsin, 54220

Canad. Anaesth. Soc. J., vol. 20, no. 3, May 1973 
metal parts of the patient system and allows easier cleaning and drainage of fluid or droplets. Figure I shows the key area of the self-contained patient system with the dark "Hersite" lining visible in ports A and B.

This type of baked phenolic lining has been used in the food industry for years. The lining will tolerate temperatures up to $450^{\circ} \mathrm{F}$, is resistent to all organic compounds and many inorganic substances. The lining has a high abrasive resistance and an excellent surface hardness. However, the surface will chip if sharp objects are used on it. The lining is not resistant to concentrated acids (e.g. nitric or sulfuric acids) while free chlorine ions (at greater than 100 parts per million) may also erode it. There are no data available on the effects of other halogens on it. Further evaluation will be done before Halothane or Methoxyflurane are exposed to this surface.

Application is by spray techniques with controlled baking to yield a smooth, hard, adherent, odorless and relatively inert lining. This type of lining may be useful in other equipment where pooling or residual droplets can cause a corrosion problem.

\section{SUMMARY}

This paper is a description of one solution to the problem of corrosion in the cast metal parts of the Engström ER300 Respirator. 